\title{
Role of COX-2 in lymphangiogenesis and restoration of lymphatic flow in secondary lymphedema
}

\author{
Shinya Kashiwagi ${ }^{1,2}$, Kanako Hosono ${ }^{1}$, Tatsunori Suzuki ${ }^{1}$, Akira Takeda ${ }^{2}$, Eiju Uchinuma ${ }^{2}$ and Masataka Majima ${ }^{1}$
}

The pathophysiology of secondary lymphedema remains poorly understood. To clarify the roles of cyclooxygenase (COX)-2 in enhancement of lymphangiogenesis during secondary lymphedema, we tested a mouse tail model and evaluated the recurrence of lymph flow. To induce lymphedema, a circumferential incision was made in the tail of anesthetized mice to sever the dermal lymphatic vessels. The maximum diameters of the tails were measured weekly. We found that the diameters of the tails around the wounds were markedly increased after surgery, and reached maximum size 2 weeks after wounding in mice without a COX-2 inhibitor, celecoxib (Celecoxib-). Expression of COX-2 in wound granulation tissues was markedly increased 1 week after surgery compared with unwounded naive control mice. In Celecoxib-, recurrence of lymphatic flow in the wound granulation tissues was detected 3 weeks after surgical treatment. In contrast, lymphatic flow was markedly suppressed in mice treated with celecoxib (Celecoxib + ). Newly formed lymphatic structures were identified in the granulation tissues formed at wounded lesions in Celecoxib-, whereas those were markedly suppressed in Celecoxib + . Interstitial tissue pressures in the distal areas of the tail wounds were markedly increased in Celecoxib + with reduced expression of vascular endothelial cell growth factor (VEGF)-C. F4/80-positive cells were accumulated to the wound granulation tissues in Celecoxib-, and the accumulation of these cells was suppressed in Celecoxib + . Prostaglandin $\mathrm{E}_{2}\left(\mathrm{PGE}_{2}\right)$ upregulated the expressions of VEGF-A and VEGF-C in cultured macrophages, but not human lymphatic microvascular endothelial cells. The present study therefore suggests that lymphangiogenesis, together with recurrence of lymph flow after surgical induction of lymphedema, is upregulated by COX-2 possibly via generation of PGs.

Laboratory Investigation (2011) 91, 1314-1325; doi:10.1038/labinvest.2011.84; published online 16 May 2011

KEYWORDS: COX-2; lymphangiogenesis; lymphedema; LYVE-1; VEGF-C

The lymphatic vasculature forms a network of vessels that drain interstitial fluid from tissues and return it to the blood. ${ }^{1,2}$ Lymphangiogenesis, the formation of lymphatic vessels from pre-existing lymphatic vessels, plays an important role in the homeostasis of interstitial fluids, metabolism, and immunity. ${ }^{1,2}$ Surgical treatment of malignant tumors, such as lymphadenectomy in patients with breast cancer, sometimes induces lymphedema that can impact quality of life. $^{3}$ The prevalence of lymphedema varies from 0 to $56 \% ;{ }^{4}$ up to $50 \%$ of survivors report symptoms consistent with lymphedema, with or without a clinical diagnosis, ${ }^{5}$ although lymph node dissection has proven to have prognostic benefits for patients with ovarian or uterine carcinoma. $^{6}$

The etiology and pathophysiology of lymphatic failure is not clearly understood, but recent studies have identified key regulators of lymphatic development and the genetic underpinnings of primary lymphedema caused by developmental lymphatic malformation. However, the pathophysiology of secondary lymphedema-including the interplay between inflammatory events, matrix remodeling, and local lymphatic response-is less well understood. The unsatisfactory status of lymphedema treatment in patients with cancer warrants an intensified search for new treatment approaches. ${ }^{1,2}$ The current therapeutic approaches of secondary lymphedema are the physical therapy, including a combination of compression, exercise, and, if possible, massage. If physical therapy fails, surgery, supermicrosurgical techniques for the anastomosis of blood or lymphatic vessels, is indicated. Although the induction of lymphangiogenesis may be a possible therapeutic approach, it is not clear to what extent therapies aimed at lymphatic regrowth will be effective for

${ }^{1}$ Department of Pharmacology, Kitasato University School of Medicine, Kanagawa, Japan and ${ }^{2}$ Department of Plastic and Aesthetic Surgery, Kitasato University School of Medicine, Kanagawa, Japan

Correspondence: Dr M Majima, MD, PhD, Department of Pharmacology, Kitasato University School of Medicine, Kanagawa 252-0374, Japan.

E-mail: mmajima@med.kitasato-u.ac.jp

Received 26 July 2010; revised 10 January 2011; accepted 29 January 2011 
the treatment of various types of secondary lymphedema. If lymphedema results from downstream blockage, such as from the surgical removal of lymph nodes, therapies that stimulate lymphangiogenesis to restore lymphatic flow may be a good option for the treatment of secondary lymphedema.

Key regulators in lymphatic development have been demonstrated by transgenic models. ${ }^{7,8}$ Vascular endothelial growth factor (VEGF) receptor-3 (VEGFR-3) is responsible for primary lymphedema. ${ }^{9}$ The recent findings suggest that targeting of molecular mechanisms of lymphangiogenesis to improve the lymphatic function may lead to a successful treatment of lymphedema by enhancing the recurrence of lymphatic flow in the secondary lymphedema situation.

We previously reported that prostaglandins (PGs), which are arachidonic acid metabolites, enhance angiogenesis during the development of chronic inflammation and tumors through the induction of a potent proangiogenic factor known as VEGF-A..$^{10-13}$ In both inflammatory and tumor models, an inducible cyclooxygenase-2 (COX-2)-derived $\mathrm{PGE}_{2}$ exerted proangiogenic activity via EP3 signaling, with the concomitant induction of VEGF-A. This effect was especially prominent in bone marrow (BM)-derived cells, which are a major component of tumor stromal tissues. We further clarified that tumor-associated lymphangiogenesis was upregulated by endogenous PGs derived from COX-2. ${ }^{14}$ In addition, upregulation of VEGFR-3 was observed in response to host PG signaling, and this was accompanied by a COX-2-dependent increase in VEGF-C expression. These data suggested that PGs are endogenous regulators of lymphangiogenesis in some pathological conditions, although it remains unknown whether endogenous $\mathrm{PGE}_{2}$ enhances lymphangiogenesis during secondary lymphedema.

In the present study, we tested the effect of celecoxib, a selective COX-2 inhibitor, on lymphangiogenesis in a model of secondary lymphedema. Molecular characterization of the lymphedema was tested in relation to the COX-2 that links to the generation of the important inflammatory mediators, PGs. The results indicate that endogenous COX-2-derived PGs stimulate lymphangiogenesis and enhance the restoration of lymphatic flow. These findings suggest that enhancement of lymphangiogenesis stimulated by PG generation and/or PG receptor signaling will be an option for the treatment of lymphedema.

\section{MATERIALS AND METHODS}

\section{Lymphedema Model in Mouse Tail}

Male C57/BL6 mice (CLEA Japan, Tokyo, Japan), 8 to 10 weeks old, were used in this study. All experimental procedures were performed in accordance with the guidelines for animal experiments in the Kitasato University School of Medicine. The study protocol was approved by the animal care and use committee $(1114,2010-119)$.
To induce lymphedema, mice were anesthetized with sodium pentobarbital $(50 \mathrm{mg} / \mathrm{kg}$, i.p.), and a $5-\mathrm{mm}$ wide circumferential incision $10 \mathrm{~mm}$ from the tail base was made through the dermis close to the tail base to sever the dermal lymphatic vessels. We removed the pre-existing lymphatic vessels without damaging the major blood vessels (arteries and veins) present central, and close to the bony/cartilaginous part of the tail. Care was taken to maintain the integrity of the major underlying blood vessels and tendons so that the tail distal to the incision did not become necrotic. Mice in the treated group were fed a diet containing celecoxib $(150 \mathrm{mg}$ per $100 \mathrm{~g}$ diet, approximately equal to $100 \mathrm{mg} / \mathrm{kg} /$ day/mouse) beginning on the day of surgery (week 0$).{ }^{15}$ Some mice received a diet containing celecoxib ( $45 \mathrm{mg}$ per $100 \mathrm{~g}$ diet, approximately equal to $30 \mathrm{mg} / \mathrm{kg} / \mathrm{day} /$ mouse). A control group of age-matched, vehicle-treated mice were maintained on a diet without celecoxib. Furthermore, another set of agematched mice without skin incisions were given the diet without celecoxib, which allowed for measurement of the baseline tail size during the time course of the analysis.

Weekly measurements of the maximum horizontal diameter of the tails at the distal edge of the incisions were performed using photographs (Nikon COOLPIX 7900, Tokyo, Japan) of the tails on a scale. The rate of reduction in the tail diameter was based on the weekly results from each mouse tested. To determine the baseline tail size of control mice during the analysis, a circumferential mark was made on the tail $10 \mathrm{~mm}$ from the tail base to represent the incision site.

\section{Tissue Sample Preparation}

Mice were killed at various times up to 3 weeks after surgical procedure. Tail tissues, including wound granulation tissues and re-epithelialized skins, were excised from the wound site under ether anesthesia. Some tissue samples were transversely cryosectioned into $10 \mu \mathrm{m}$-thick sections for immunostaining and others were immediately analyzed by real-time PCR.

\section{Microlymphangiography}

Mice were anesthetized as described above, and the integrity of the lymphatic vasculature of the tail was examined by fluorescence microlymphangiography. ${ }^{16}$ In this procedure, a fluorescently labeled macromolecule $(2000 \mathrm{kDa}$ FITC-dextran, $2 \mathrm{mg} / \mathrm{ml}$; Molecular Probes, Carlsbad, CA, USA) was injected subcutaneously to the top of the tails. Because of its large size, the tracer is taken up by the lymphatics but excluded from the blood vasculature. As the fluorescent tracer was transported by the lymphatic vessels, it was clearly visible within dermal lymphatic capillaries, thus providing a clear visualization of lymphatic functionality. The filling of the lymphatic vasculature was monitored for $30 \mathrm{~min}$ with a fluorescence microscope (VHX-1000, KEYENCE, Osaka, Japan) with equal exposure times for each mouse. The arbitrary units of fluorescence intensity were analyzed with VHX-1000 software (KEYENCE), and were compared between the two groups. 


\section{Immunofluorescent Histochemistry}

At 3 weeks after surgery, tail samples were isolated and thin sections $(10 \mu \mathrm{m})$ were prepared by Kawamoto's method. ${ }^{17}$ The sections were blocked with 1\% BSA-PBS and then incubated with a mixture of anti-mouse LYVE-1 (Abcam, Cambridge, UK) and anti-mouse CD31 (BD Pharmingen, San Diego, CA, USA). After washing in PBS, the sections were incubated with a mixture of Alexa Fluor $\mathbb{R} 488$ Goat Anti-rabbit IgG and Alexa Fluor 568 Goat Anti-rat IgG. Cross-reaction of secondary antibodies against IgG species was also examined by reversing the combination of primary and secondary antibodies. Images were captured with a confocal scanning laser microscope (LSM710; Carl Zeiss, Jena, Germany) and computer-assisted morphometric analyses of lymphatic vessels were performed using ZEN 2008 software as described previously. ${ }^{15}$

In some samples, we used a mixture of rat anti-mouse F4/ 80 monoclonal IgG antibody (Santa Cruz Biotechnology, Santa Cruz, CA, USA) and anti-mouse COX-2 monoclonal IgG antibody (Abcam) with use of Alexa Fluor 488 Goat Anti-rabbit IgG and Texas Red $($ B Donkey Anti-goat IgG. Macrophage accumulation was also tested by rat anti-mouse F4/80 monoclonal IgG antibody (Santa Cruz Biotechnology) with use of an Alexa Fluor 568 Goat Anti-rat IgG.

\section{Quantitative Real-Time RT-PCR}

Quantitative real-time RT-PCR of total RNA isolated from the tail samples was performed as described previously. ${ }^{15}$
Total RNA was extracted from mouse tissues using TRIzol@ (Invitrogen, San Diego, CA, USA) and single-stranded cDNA was generated from $1 \mu \mathrm{g}$ of total RNA via reverse transcription with ReverTra Ace- $\alpha$-TM (TOYOBO, Osaka, Japan). Real-time PCR primers were designed using Primer3 software (http://primer3.sourceforge.net/) based on GenBank data and are listed in Table 1. Quantitative PCR amplification was performed using SYBR@ Premix Ex Taq ${ }^{\mathrm{TM}}$ (TaKaRa Bio, Shiga, Japan) with the Chromo4 real-time PCR detection system (Bio-Rad, Hercules, CA, USA). Threshold cycle (Ct) values were processed for further calculations according to the comparative $\mathrm{Ct}$ method. Expression levels of target genes were normalized to the housekeeping gene $G A P D H$, giving the $\Delta \mathrm{Ct}$ value. Finally, the gene expression level was calculated as $2-\Delta \mathrm{Ct}$, giving the final value.

\section{Determination of Interstitial Pressure in Subcutaneous Tail Tissues}

At 3 weeks after surgery, the interstitial pressure in the tail tissues was determined with a $23 \mathrm{G}$ needle connected to a lowpressure transducer $20 \mathrm{~mm}$ distal to the peripheral edge of the tail skin wound. Pressure is expressed as $\mathrm{mm} \mathrm{Hg}$. We preliminary tested the pressure distal to the wounds. Up to $20 \mathrm{~mm}$ distance, there was no marked change in the interstitial pressures. To avoid the mechanical stimuli to the wounds, we selected this distance throughout the present study.

Table 1 Oligonucleotides used as primers for RT-PCR

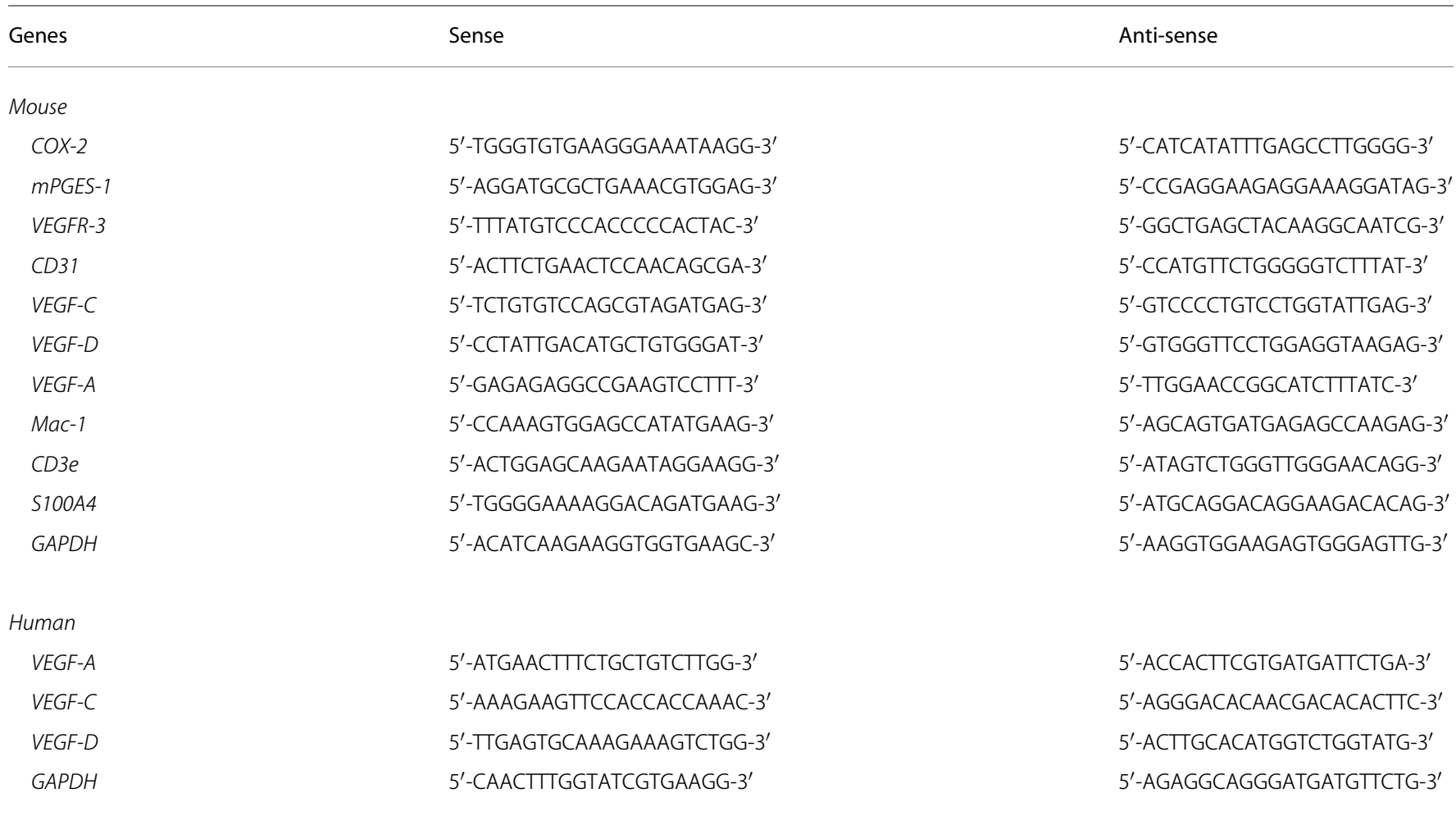




\section{Cell Culture}

Human lymphatic microvascular endothelial cells (HMVECdLyNeo: CC-2812) were obtained from TaKaRa. They were cultured in $\mathrm{EGM}^{\mathbb{R}}-2-\mathrm{MV}$ BulletKit ${ }^{\mathbb{R}}$ DMEM supplemented with $5 \%(\mathrm{v} / \mathrm{v}) \mathrm{FBS}$ at $37^{\circ} \mathrm{C}$ in $5 \%$ humidified $\mathrm{CO}_{2}$, in the presence of $100 \mathrm{U} / \mathrm{ml}$ penicillin and $100 \mu \mathrm{g} / \mathrm{ml}$ streptomycin.

Peritoneal macrophages in C57/BL6 mice were elicited using thioglycolate and were obtained via lavage of the peritoneal cavity, using $3 \times 5 \mathrm{ml}$ of PBS. Peritoneal exudate cells were washed, suspended in RPMI-1640 medium containing $10 \%$ FBS, $100 \mathrm{U} / \mathrm{ml}$ penicillin, and $100 \mu \mathrm{g} / \mathrm{ml}$ streptomycin, and enriched for macrophages by adhesion for $2 \mathrm{~h}$ (six-well tissue culture plates at $2 \times 10^{6}$ cells/well).

The resulting peritoneal macrophages and HMVEC-dLyNeo (six-well tissue culture plates at $3 \times 10^{5}$ cells /well) were stimulated with $\mathrm{PGE}_{2}$ for $24 \mathrm{~h}$. After $24 \mathrm{~h}$ of incubation, PremixWST-1 (TaKaRa Bio) was added. At $3 \mathrm{~h}$ after incubation, absorbance at $450 \mathrm{~nm}$ was determined by SoftMax Pro Multi plate Reader (Molecular Devices, CA, USA) in comparison with that at $650 \mathrm{~nm}$ as a marker of cell proliferation. Total RNA was extracted from these cultured cells using TRIzol (Invitrogen), and relative expressions of VEGF isoforms were determined.

\section{Statistical Analysis}

Data are expressed as means \pm s.e.m. Comparison of multiple groups was performed by factorial analysis of variance (ANOVA) followed by Scheffe's test. Comparison between two groups was performed by Student's $t$-test. $P$-values $<0.05$ were considered statistically significant.

\section{RESULTS}

\section{Development of Lymphedema in Mouse Tails and} Upregulation of COX-2 in Wound Granulation Tissues

After the surgical removal of subcutaneous tissue from the basal region of the tails, granulation tissues appeared in the wounds within 2 days of the operation. In vehicle-treated mice, the wounds were covered with epithelial cells 3 weeks after surgical treatment (Figure 1a). The diameters of the distal edge of the wounds were markedly increased after the surgery, and they reached maximum size at 2 weeks after surgery (Figure 1b). Changes in tail diameter in celecoxibtreated mice followed essentially the same time course as those observed in mice without celecoxib, showing peak levels 2 weeks after the surgical removal of subcutaneous tissues (celecoxib-treated mice 2 weeks after surgery; $5.5 \pm 0.2 \mathrm{~mm}, n=10)$. In mice without celecoxib, the maximum diameters of the tails decreased after 2 weeks (Figure 1b). When the reduction rates after the peak of edema were determined (Figure 1c), the reduction of edema in terms of the maximum diameter of the tails in celecoxib-treated mice $(100 \mathrm{mg} / \mathrm{kg} /$ day $)$ was significantly $(P=0.041$, and $P=0.018)$ suppressed in comparison with mice without celecoxib at 3 and 4 weeks after the surgery (Figure 1c), although this suppression was not seen at later time points. The reduction rate in mice treated with $30 \mathrm{mg} / \mathrm{kg} /$ day was essentially the same as that seen in mice with $100 \mathrm{mg} / \mathrm{kg} /$ day. The decrease in edema in mice treated with $30 \mathrm{mg} / \mathrm{kg} /$ day at 4 weeks after surgery was $88 \pm 2 \%(n=10)$.

The expression of COX- 2 in wound granulation tissues was markedly increased in both mice without celecoxib and celecoxib-treated mice at 1 week after surgery compared with unwounded naive control mice (Figure 1d). At 1 and 2 weeks after surgical treatment, the expressions of COX-2 were significantly reduced in celecoxib-treated mice compared with mice without celecoxib (Figure 1d). Despite the increase in COX-2 mRNA in early stages, the expression of an inducible prostaglandin E synthase (mPGES-1) was unchanged throughout the experimental period (Figure 1e).

\section{Role of COX-2 in the Restoration of Lymphatic Flow and Reduction of Interstitial Pressure}

To evaluate the functionality of the lymphatics generated in the proliferative granulation tissues, we injected FITC-dextran into the subcutaneous tissues of the distal portion of the tails. In mice without celecoxib, visualized lymphatic flow in wound granulation tissues was detected 3 weeks after surgical treatment (Figure 2a). Lymphatic flow was evident in the base of the tails over the wounded areas $30 \mathrm{~min}$ after the dye injection (Figure 2a). In contrast, lymphatic flow was markedly suppressed in mice treated with celecoxib $30 \mathrm{~min}$ after the dye injections (Figure 2b). When the accumulated intensity of the fluorescence just proximal to the wounded area (indicated by squares in Figure $2 \mathrm{a}$ and $\mathrm{b}$ ) was determined, the fluorescence intensity was markedly and significantly $(P<0.001)$ suppressed with celecoxib treatment (Figure 2c).

When the interstitial tissue pressures in the region of the tails distal to the wounds were determined, the pressures in vehicle-treated mice at $1,3,4,5$, and 6 weeks after surgical treatment were markedly increased with celecoxib treatment (Figure 2d).

\section{Role of COX-2 in LYVE-1-Positive Lymphatic Structure Formation in Wound Granulation Tissues}

Transverse sections of the tail wounds and naive tails were stained with HE and LYVE-1/CD31 antibodies (Figure 3a-h). At 3 weeks after the surgical removal of subcutaneous tissues, LYVE-1-positive lymphatic structures (green) were identified in the granulation tissues formed at the tail lesions in mice without celecoxib (Figure $3 \mathrm{e}$ and $\mathrm{g}$ ). The granulation tissues were also rich in CD31-positive blood vessels (red) in mice without celecoxib (Figure 3e and g). The formation of both LYVE-1-positive lymphatic structures and CD31-positive blood vessels in wound granulation tissues was markedly suppressed with celecoxib treatment (Figure $3 \mathrm{f}$ and $\mathrm{h}$ ). When the density of lymphatic structures was determined in terms of vessel number/granulation tissue area, celecoxib treatment suppressed the density of lymphatic structures by $61 \%$ (Figure 3i). 

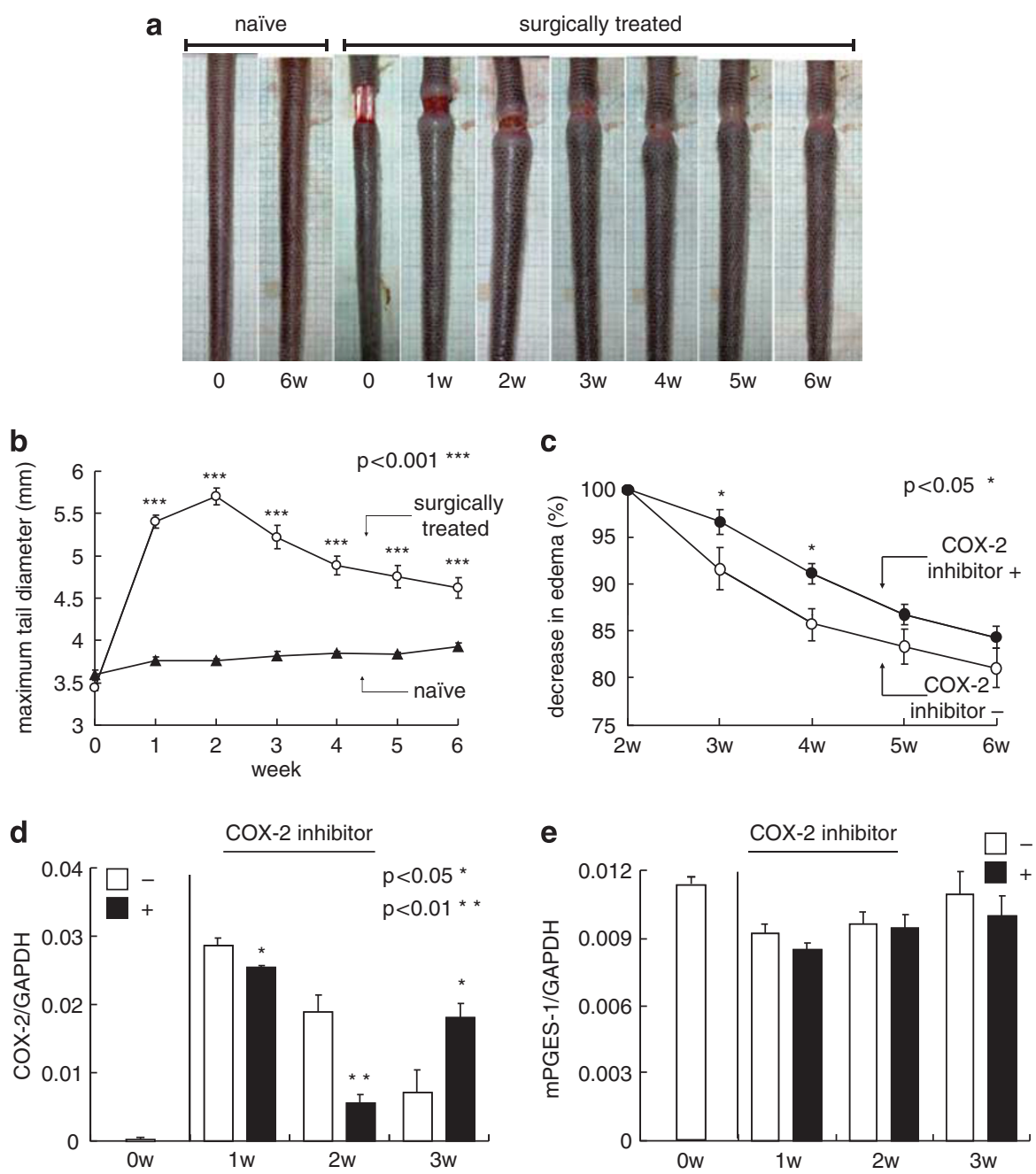

Figure 1 Development of lymphedema in mouse tails and upregulation of COX-2 in wound granulation tissues. (a) Typical results of lymphedema. Naive: the tails of age-matched mice without surgery. Wounds were covered with epithelial cells in mice without celecoxib at 3 weeks after surgery. (b) Changes in the maximum diameters of tails. Values are expressed as the means \pm s.e.m. $(n=10)$. ${ }^{* *} p<0.001$ compared with naive mice. (c) Rate of reduction in the maximum diameters of the tails. Values are expressed as the means \pm s.e.m. $(n=10) .{ }^{\star} P<0.05$ compared with mice without celecoxib. (d) Expression of COX-2 in wound granulation tissues. Values are expressed as the means \pm s.e.m. $(n=5)$. ${ }^{*} P<0.01$ compared with mice without celecoxib. (e) Expression of mPGES-1 in wound granulation tissues. Values are expressed as the means \pm s.e.m. $(n=5)$.

\section{Changes in mRNA Levels of VEGF Isoforms, VEGFR-3, and CD31 in Wound Granulation Tissues}

mRNA levels in the granulation tissues formed at wounded lesions of the tails were measured by real-time PCR (Figure 4). The mRNA levels of VEGF-C increased gradually after surgical treatment in mice without celecoxib (Figure 4a). The same trend was evident in celecoxib-treated mice; however, the levels were lower than those in mice without celecoxib (Figure 4a). The difference between the mRNA levels in each group at 1 week after surgical treatment was statistically significant $(P=0.019$; Figure $4 a)$. In contrast, expression of VEGF-D, another pro-lymphangiogenic factor, was largely unchanged throughout the experimental period (Figure $4 \mathrm{~b})$. VEGF-A expression was significantly $(P=0.015)$ suppressed in celecoxib-treated mice at 1 week after surgical treatment (Figure 4c). VEGFR-3 expression peaked 2 weeks after surgical treatment in mice without celecoxib (Figure 4d), but was significantly $(P=0.002$, and $P=0.006$ ) suppressed by celecoxib treatment at 2 and 3 weeks after surgical treatment (Figure 4d). Expression of the blood vessel endothelial marker, CD31, was also significantly $(P=0.041$, and $P=0.014$ ) suppressed by celecoxib treatment at 2 and 3 weeks after surgery (Figure 4e).

\section{Analysis of Cellular Profiles of Wound Granulation Tissues and Effects of a COX-2 Inhibitor}

mRNA levels of the hematopoietic lineage markers in the granulation tissues formed at tail wound lesions were analyzed by real-time PCR and immunohistochemistry (Figure 5). The mRNA levels of Mac-1 in the granulation tissues in mice without celecoxib were increased gradually after surgery in comparison with tissues soon after the 
a

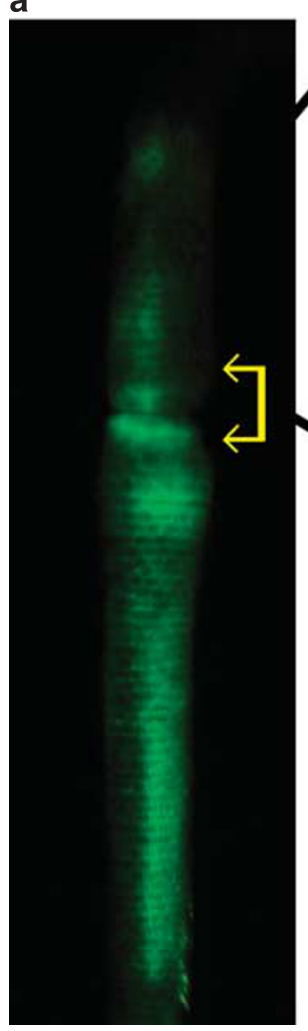

coX-2 inhibitor - b

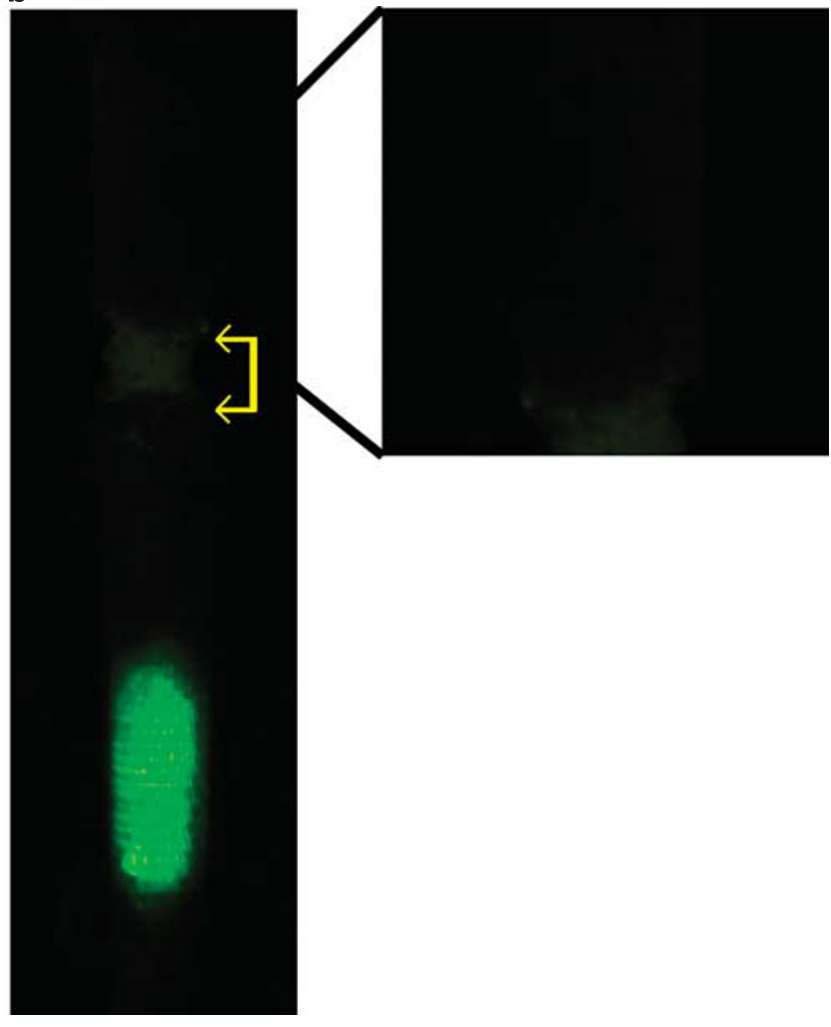

COX-2 inhibitor +
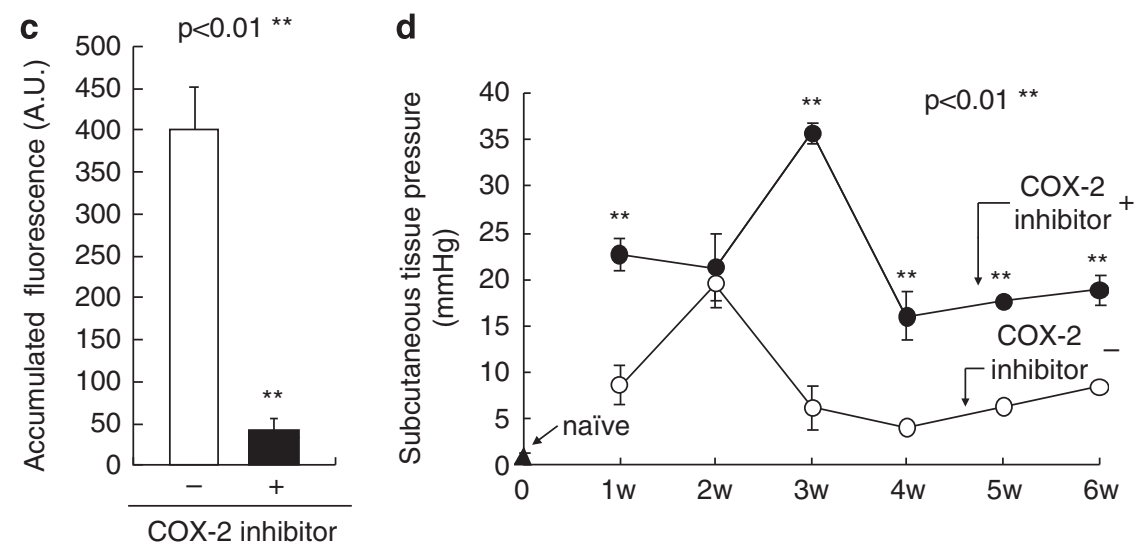

Figure 2 Role of COX-2 in restoration of lymphatic flow and reduction in interstitial pressure. (a, b) Lymphatic flow estimated by subcutaneous injection of FITC-dextran at the distal portion of the tails. Typical results $30 \mathrm{~min}$ after the dye injections are shown. Yellow arrows indicate the wounded lesions.

Fluorescence intensity was determined in the proximal portions of the tails (white squares). Images were obtained 3 weeks after surgery. (c) Accumulated fluorescence intensity from mice without celecoxib, and celecoxib-treated mice at 3 weeks after surgery. Values in the white squares in (a, $\mathbf{b})$ are expressed as the means \pm s.e.m. $(n=4)$. ${ }^{* * P}<0.01$ compared with mice without celecoxib. AU: arbitrary units. (d) Time course of the changes in interstitial tissue

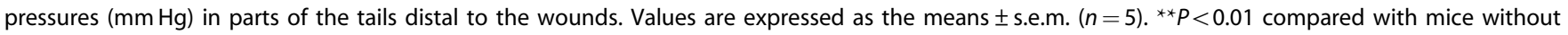
celecoxib.

wounding ( 0 weeks, Figure $5 a)$. The difference was statistically significant at 1 week $(P=0.026)$ and 2 weeks $(P=0.024)$ after the surgery (Figure $5 \mathrm{a})$. In contrast, the mRNA levels of CD3e and S100A4 were decreased significantly after surgery (Figure 5a). When F4/80 immunohistochemistry was performed 7 days after surgery, F4/80-positive cells were accumulated in the granulation tissues formed around the wounds together with BMs in the tails near the wounds (Figure 5b, upper panel). Celecoxib treatment markedly reduced the accumulation of F4/80positive cells in both the granulation tissues and the BMs (Figure 5b, lower panel). F4/80-positive macrophage concentration in the granulation tissues was significantly $(P=0.003)$ reduced 7 days after surgery (Figure $5 c)$. When 
a
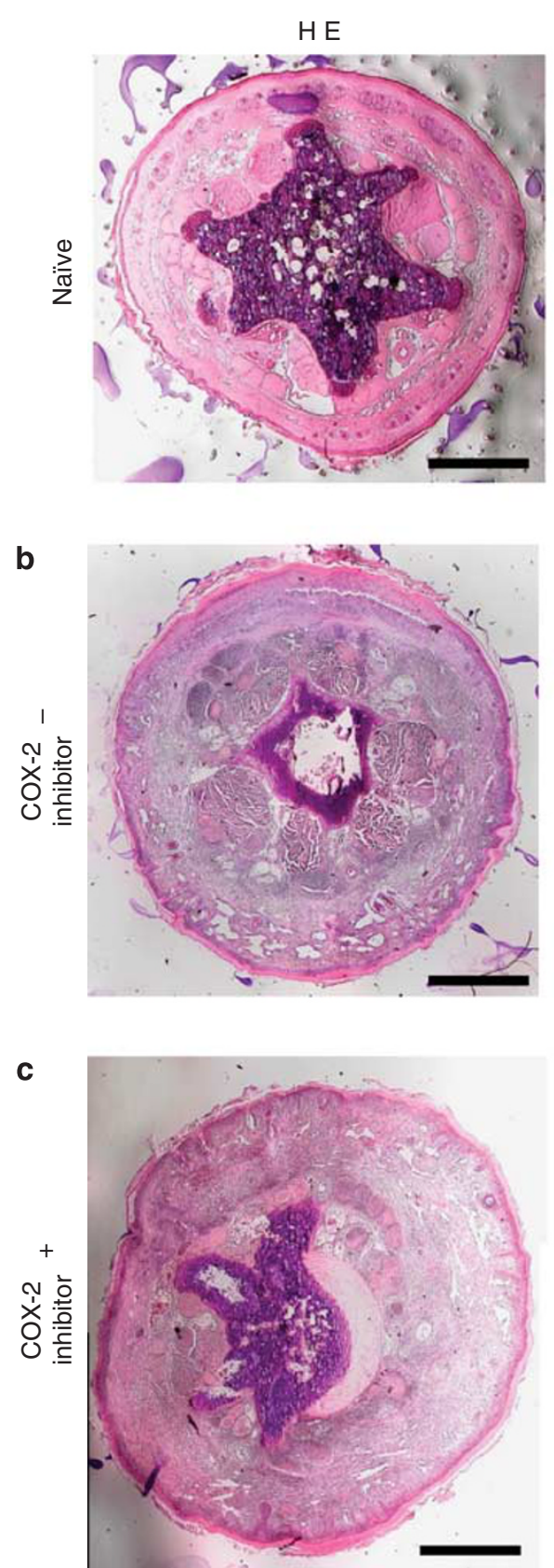

d

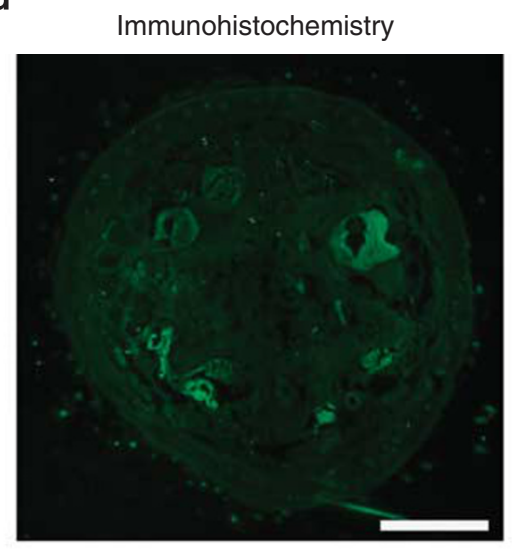

e

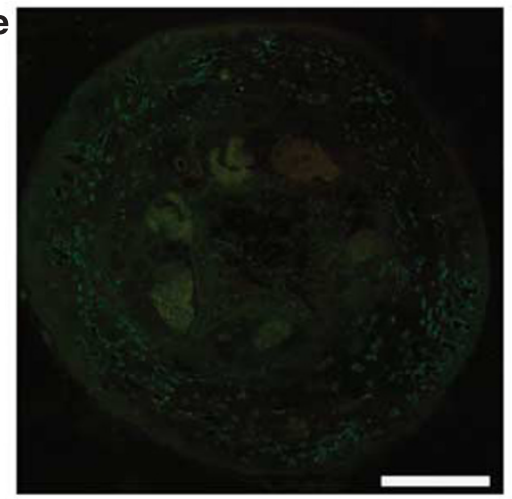

f

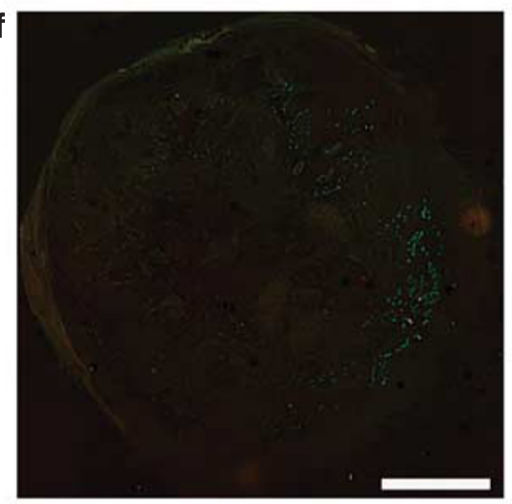

i

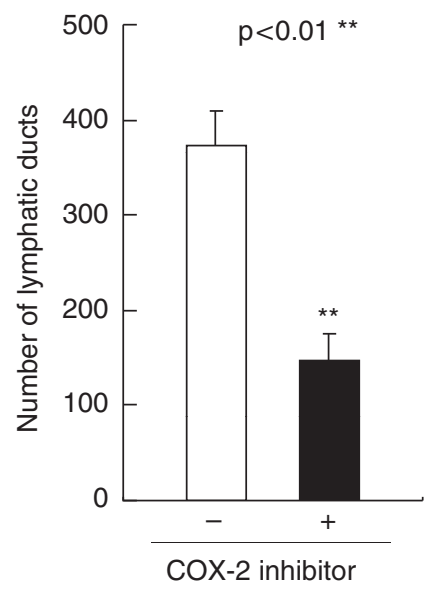

g

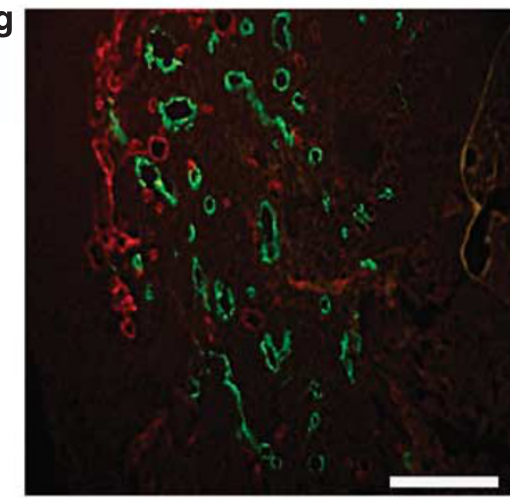

h

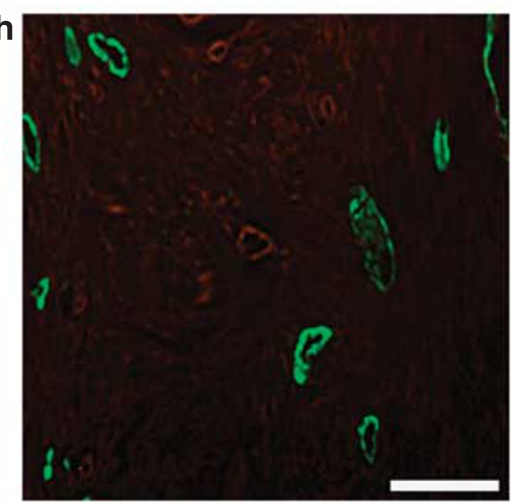

Figure 3 Role of COX-2 in LYVE-1-positive lymphatic structure formation. (a-c) Typical HE staining of the transverse sections of the wounded tails 3 weeks after surgery from naive mice, mice without celecoxib, and celecoxib-treated mice, respectively. Bars indicate $1 \mathrm{~mm}$. (d-f) Typical LYVE-1 immunostaining of the transverse sections of wounded tails 3 weeks after surgery from naive mice, mice without celecoxib, and celecoxib-treated mice, respectively. Bars indicate $1 \mathrm{~mm}$. (g, h) High-magnification images of panels e and f. Red: CD31; Green: LYVE-1. Bars indicate $200 \mu \mathrm{m}$. (i) Density of lymphatic structures in terms of vessel numbers/total transverse area of the granulation tissues at 3 weeks after surgery. Values are expressed as the means \pm s.e.m. $(n=5)$. ${ }^{*} P<0.01$ compared with mice without celecoxib.

double immunostaining with F4/80 antibody and COX-2 antibody was performed in the granulation tissues 7 days after surgery (Figure 5d), a large number of COX-2-positive cells were found to express F4/80 (Figure 5d), suggesting that F4/80-positive macrophages accumulated around the wounds enhanced lymphangiogenesis in a COX-2-dependent manner.

\section{Effects of $\mathrm{PGE}_{2}$ on Proliferations of HMVECs and Macrophages and Expressions of VEGF Isoforms}

We finally tested the in vitro effects of $\mathrm{PGE}_{2}$ on proliferations of HMVECs and macrophages (Figure 6). Compared with vehicle solution $(0 \mathrm{nM}), \mathrm{PGE}_{2}$ did not enhance the cell proliferation at concentrations of 1 and $10 \mathrm{nM}$ (Figure 6a). High 
concentration $(100 \mathrm{nM})$ showed marginal but significant $(P=0.003)$ proliferative effect on HMVECs. In contrast, $\mathrm{PGE}_{2}$ significantly $(P=0.003, P<0.001$, and $P<0.001)$ suppressed the proliferation of the macrophages obtained from the mouse peritoneal cavity in a dose-dependent manner (Figure 6e).

Addition of $\mathrm{PGE}_{2}$ to HMVECs did not increase the mRNA levels of VEGF isoforms, VEGF-A, VEGF-C, and VEGF-D markedly (Figure 6b-d). In contrast, $\mathrm{PGE}_{2}$ increased the expressions of VEGF-A and VEGF-C in a dose-dependent manner, whereas it did not the increase the expressions of VEGF-D (Figure 6f-h).

\section{DISCUSSION}

The lymphatic system is a vascular network that maintains tissue fluid homeostasis and mediates regional inflammatory responses. When the anatomic and functional integrity of the lymphatic vasculature is impaired, the resulting loss of fluid transport capacity leads to lymphedema, the most readily recognizable consequence of lymphatic vascular incompetence. The potential for therapeutic lymphangiogenesis has been widely anticipated after the identification of endogenous factors that enhance this event. ${ }^{2}$ The objectives of the present study were to examine the role of COX-2derived PGs in the enhancement of lymphangiogenesis in an acquired lymphedema model, and the therapeutic potential of PGs to enhance the restoration of lymph flow.

In the present experiment, we utilized a murine tail lymphedema model to investigate the role of COX-2 in the restoration of lymph flow (Figure 2) and lymphangiogenesis (Figure 3). Removal of the pre-existing lymph vessels in the subcutaneous tissues resulted in the formation of wound granulation tissues that supported the regeneration of lymphatics (Figure 3). This model is a useful experimental platform for elucidating the mechanisms of the disease and evaluating potential therapies. ${ }^{18}$ In previous studies, administration of VEGF-C to promote therapeutic lymphangiogenesis was shown to reduce edema volume and have beneficial effects on tissue architecture. ${ }^{19,20}$ Molecular characterization of the tissues with lymphedema revealed the prominence of inflammatory mediators affecting the inflammatory nature of this acquired microvascular disorder. ${ }^{21-23}$ Lymph stasis is known to induce the tissue destruction associated with lymphedema. Inflammation in lymphedema may be in response to loss of lymphatic vascular integrity, and thus a rational target for intervention in this experimental model. In the present study, we first clarified that the recurrence of lymph flow in the wound granulation tissues was increased by COX-2 activity with increased formation of LYVE-1-positive lymphatic-like structures (Figure 2). COX-2 mRNA levels were markedly increased in tail granulation tissues in the early phases of the wound healing process (Figure 1d). COX-2 catalyzes $\mathrm{PGG}_{2} / \mathrm{H}_{2}$ formation from the released arachidonic acid. There are some reports that describes upregulation of COX-2 by $\mathrm{PGE}_{2}{ }^{24-26}$ Thus, it is possible that celecoxib treatment blunts the expressions of COX-2 in the granulation tissues in this model. However, in the present experimental settings, mRNA levels of COX-2 in the granulation tissues may be reduced because of the reduced accumulation of macrophages (Figure $5 b$ and $c$ ), although we cannot rule out the possibility that there is a feedback mechanism between the COX-2-derived PGs and COX expression at 1 and 2 weeks after surgery. The reduction was more prominent at 2 weeks after the surgery (Figure 1d), suggesting that both reduced upregulation of COX-2 and reduced accumulation of COX-2-postive macrophages explain
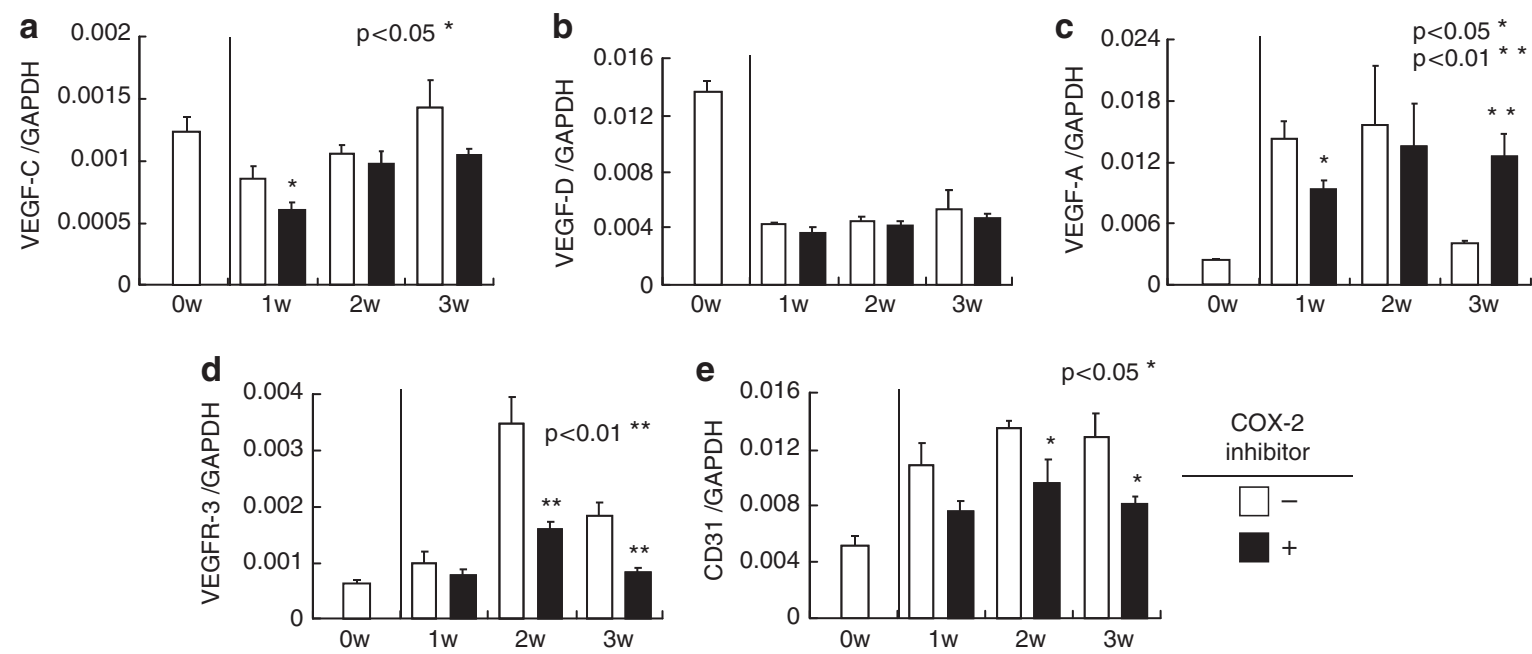

Figure 4 Changes in mRNA levels of VEGF isoforms, VEGFR-3, and CD31 in wound granulation tissues. (a) VEGF-C, (b) VEGF-D, (c) VEGF-A, (d) VEGFR-3 and (e) CD31 mRNA levels in the granulation tissues formed at wounded lesions were determined by real-time PCR and were expressed relative to mRNA levels of GAPDH. The values at 0 weeks indicate the values from naive mice. The values from celecoxib-treated mice (closed columns) were compared with those from mice without celecoxib (open columns) at the same time points. Values are expressed as the means \pm s.e.m. $(n=5)$. ${ }^{\star} P<0.05$;

$* * P<0.01$ compared with mice without celecoxib. 


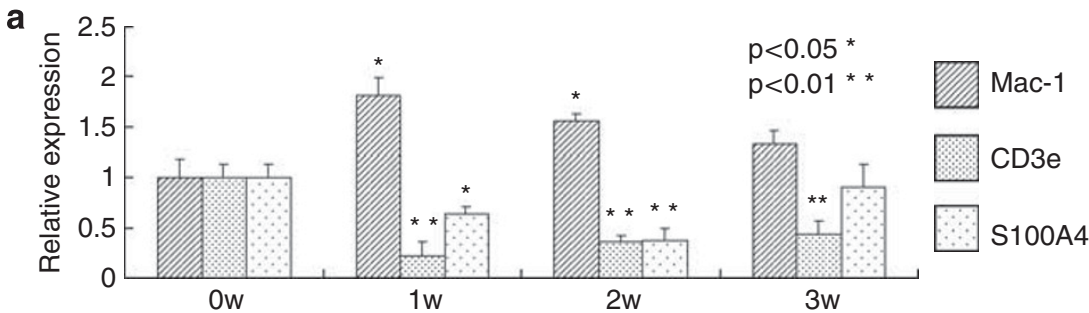

b
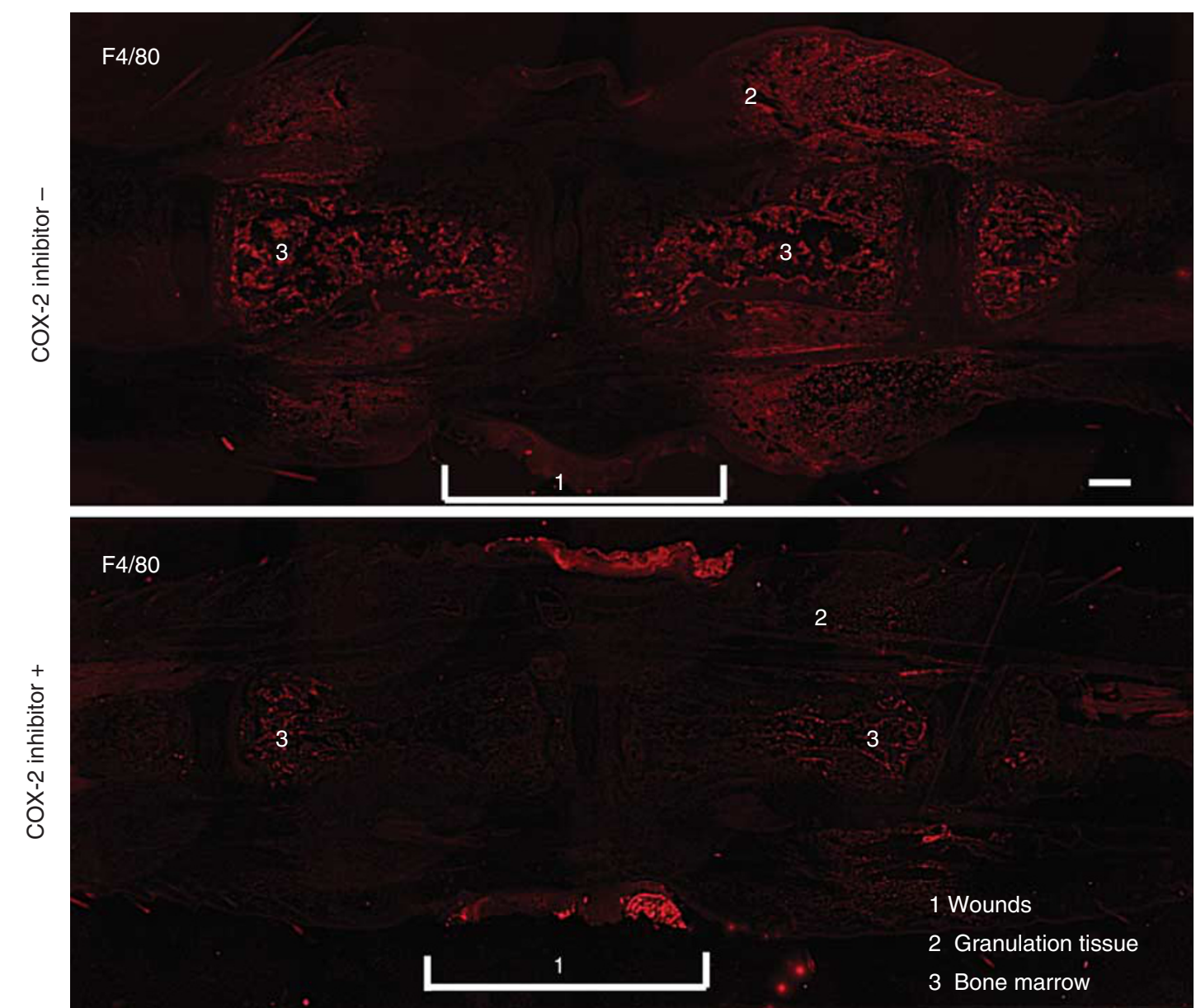

C

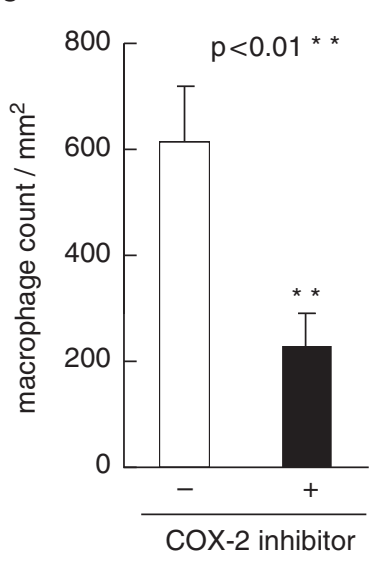

d

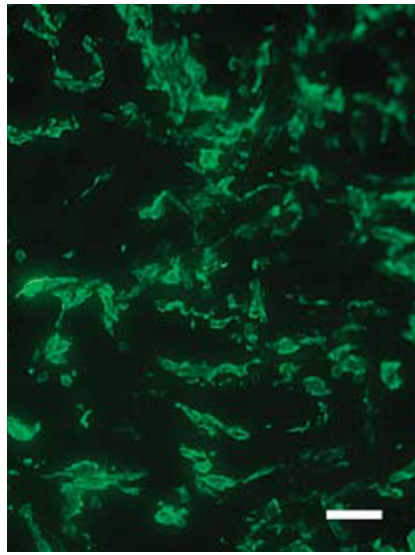

coX-2

Merge

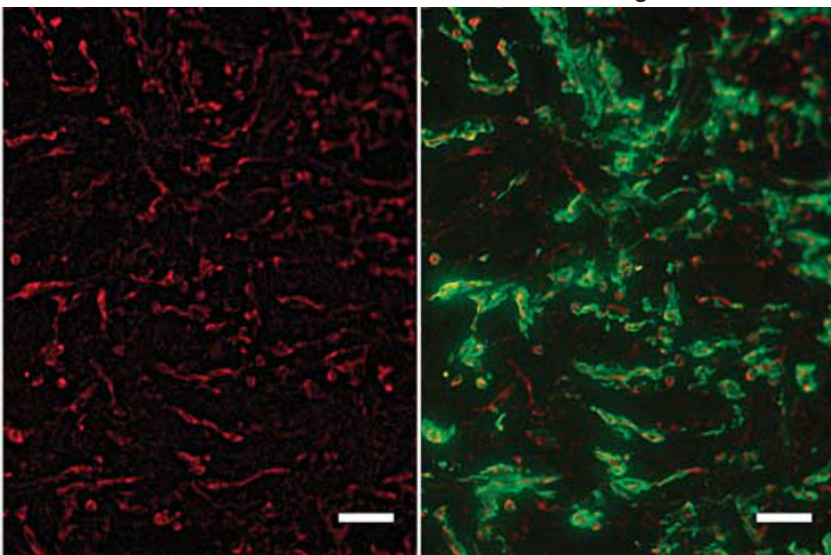


reduced mRNA levels of COX-2 in the granulation tissues. There was no reduction in COX-2 mRNA levels in celecoxib-treated mice at 3 weeks after the surgery, suggesting that COX-2 induction is transient in this model. It is interesting that we did not find the upregulation of mPGES-1. This suggests that COX-2 is a rate-limiting factor to generate $\mathrm{PGE}_{2}$. As VEGF-C expression was suppressed by celecoxib (Figure 4), the inhibition of VEGFR-3 expression seen later may be a result of reduced VEGF-C expression. The same was true of VEGF-A expression (Figure 4). VEGF-A has been reported to stimulate lymphangiogenesis via increased recruitment of macrophages that are the source of VEGF-C. ${ }^{27}$ This suggests that the COX-2-dependent increase in VEGF-C and/or VEGF-A may be important for upregulation of VEGFR-3 and restoration of lymph flow.

We previously reported that COX-2 contributed to tumor growth and angiogenesis. ${ }^{12,13}$ However, little is known about the direct contribution of COX-2 to lymphedema-associated lymphangiogenesis, although positive correlations between
COX-2 expression in tumor tissues and lymphangiogenesis and lymph node metastasis have been reported for several human cancers, ${ }^{28-30}$ as well as the effect of COX-2 inhibition on lymphangiogenesis in a tumor implantation model. ${ }^{14}$ In a study utilizing a nonselective COX inhibitor in a mouse tail lymphedema model, ketoprofen treatment normalized the histopathology with increased TNF- $\alpha$ expression and VEGF-C expression. ${ }^{31}$ The surprising difference between the effect of COX-2 inhibition on VEGF-C expression in that study and ours suggests that the selectivity of COX inhibitors is important.

An interesting phenotype observed in response to COX-2 inhibition was the reduced granulation tissue formed as a result of reduced recruitment of inflammatory cells to the wounds (Figure 3j). As far as we tested, the major cellular component accumulated during the lymphangiogenesis was the macrophages, and this accumulation was COX-2 dependent (Figure 5). This was quite consistent with that observed in sponge granulation tissues in our previous
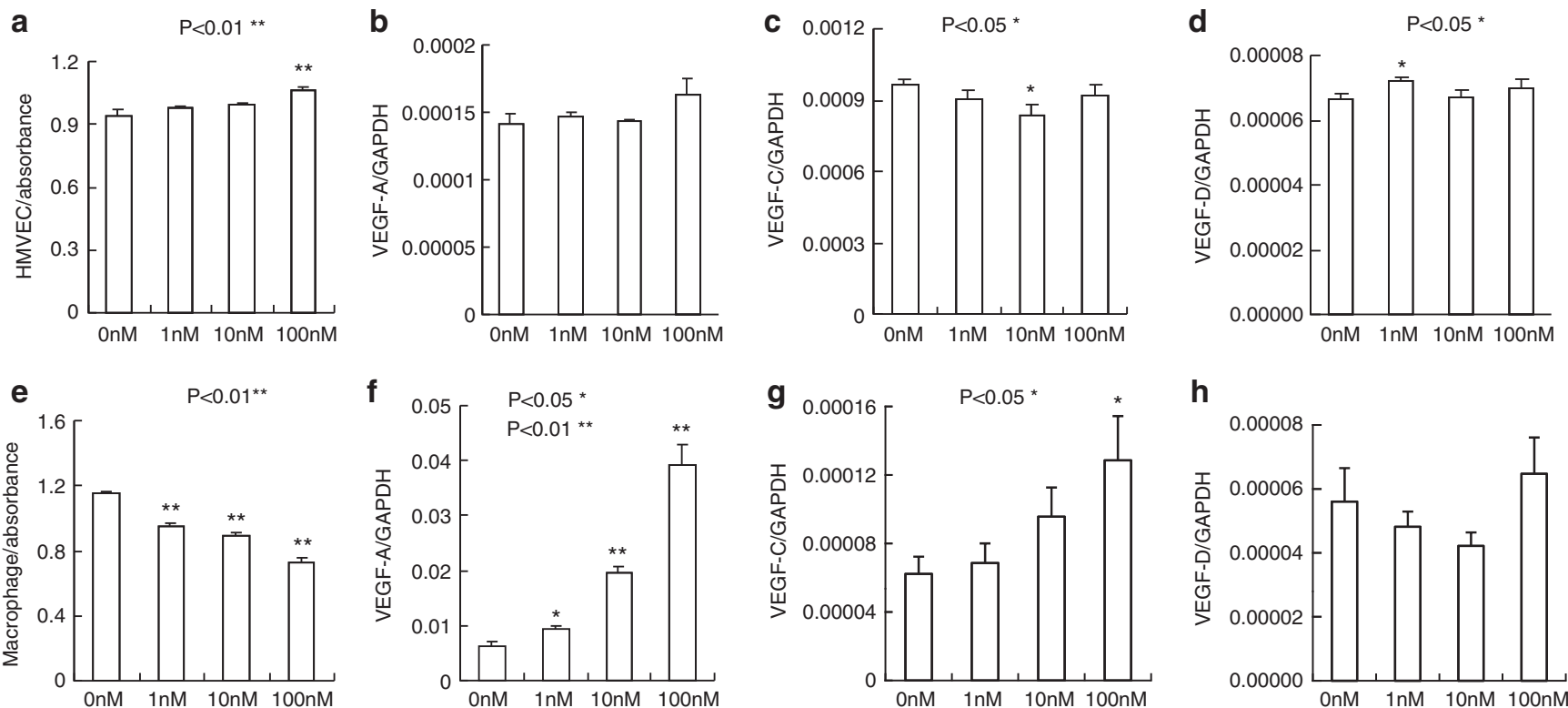

Figure 6 Effects of prostaglandin $E_{2}$ on proliferations of cultured human lymphatic microvascular endothelial cells (HMVECs) and macrophages and expressions of vascular endothelial growth factor (VEGF) isoforms. (a, e) Effects of prostaglandin $E_{2}$ on proliferations of lymphatic endothelial cells (HMVECs) and macrophages. Proliferation was determined with PremixWST-1 (TaKaRa Bio) by absorbance at $450 \mathrm{~nm}$ in comparison with that at $650 \mathrm{~nm}$. (b-d) VEGF isoform expressions in HMVECs after the incubation with vehicle solution $(0 \mathrm{nM})$ and $\mathrm{PGE}_{2}(1,10$, and $100 \mathrm{nM})$. ( $\left.\mathbf{f}-\mathbf{h}\right)$ VEGF isoform expressions in macrophages after the incubation with vehicle solution $(0 \mathrm{nM})$ and $\mathrm{PGE}_{2}(1,10$, and $100 \mathrm{nM})$. Values are expressed as the means \pm s.e.m. $(n=5)$. ${ }^{\star} P<0.05$; ${ }^{*} \mathrm{P}<0.01$ compared with the values at $0 \mathrm{nM}$.

Figure 5 Changes in mRNA levels of cell surface markers in wound granulation tissues and F4/80-COX-2 double immunostaining. (a) Relative changes in mRNA levels in cell surface markers in the granulation tissues formed at wounded lesions. Mean expressed levels of Mac-1, CD3e, and S100A4 relative to mRNA levels of GAPDH in the tail tissues soon after the surgical treatment ( 0 weeks) were defined as 1 . Values are expressed as the means \pm s.e.m. $(n=5)$. ${ }^{\star} P<0.05 ;{ }^{*} P<0.01$ compared with the values at 0 weeks. (b) The localization of F4/80-positive cells in the tail tissues 1 week after the surgery. The accumulation of F4/80-positive cells seen in the granulation tissues and bone marrows in mice without celecoxib (upper panel) was markedly suppressed by celecoxib treatment (lower panel). Scale bars indicate $500 \mu \mathrm{m}$. (c) F4/80-positive macrophage concentration in the granulation tissues 7 days after surgery. Values are expressed as the means \pm s.e.m. $(n=8) .{ }^{*} P<0.01$ compared with the values in mice without celecoxib. (d) Double immunostaining with F4/80 antibody and COX-2 antibody in the granulation tissues 7 days after surgery. Scale bars indicate $50 \mu \mathrm{m}$. A large number of COX-2-positive cells were found to express F4/80. 
study. ${ }^{32}$ We reported that the replacement of wild-type BM with BM cells (BMCs) from green fluorescent protein (GFP) transgenic mice revealed that the formation of granulation tissue around the sponge implants developed via the recruitment of BMCs. ${ }^{32}$ A COX-2 inhibitor, celecoxib, also inhibited this recruitment. FACS analysis of the granulation tissues after treatment with collagenase revealed that the recruitment of Mac-1-positive macrophage fraction was inhibited by celecoxib. ${ }^{32}$

The prostanoids relevant to the enhancement of lymphangiogenesis and recurrence of lymph flow were not identified in the present study. But, we had seen that $\mathrm{PGE}_{2}$ is an active prostanoid to induce angiogenesis in mouse sponge implantation model that mimic the wound granulation tissues. ${ }^{33}$ Furthermore, the same was true in skin wound healing models. ${ }^{33}$ The activation of adenylate cyclase linking to some of the EP receptor subtypes resulted in the enhancement of angiogenesis in the sponge model. ${ }^{34}$ Selective knockdown of EP3 performed by BM transplantation with BMCs isolated from EP3 knockout (EP3) mice reduced sponge-induced angiogenesis, as estimated by mean vascular number and $\mathrm{CD} 31$ expression in the granulation tissues. ${ }^{32}$ This reduction in angiogenesis in EP3(-/-) BM chimeric mice was accompanied by reductions in the recruitment of BMCs, especially of Mac-1-positive cells and Gr-1-positive cells. ${ }^{32}$ These results indicate that the recruited BMCs that express the EP3 receptor have a significant role in enhancing angiogenesis during chronic proliferative inflammation. ${ }^{32}$ Few studies have examined VEGF-C induction, although VEGF-D expression is known to be induced by cell-cell contact mediated by cadherin-11. ${ }^{35}$ Sequences upstream of the VEGF-C translation start site were found to contain consensus binding sites for the AP-2 transcription factor, suggesting that the cAMP-dependent protein kinase activates the AP-2 transcription factor to regulate VEGF-C transcription. ${ }^{36,37} \mathrm{Be}$ cause COX-2 inhibition reduced VEGF-C expression in the early stages of the experiment (Figure 4a), but not VEGF-D (Figure $4 \mathrm{~b}$ ), VEGF-C may be the growth factor responsible for enhancement of lymphangiogenesis. The transcription factors and regulatory promoter elements that control VEGF-D gene expression have not been fully identified; ${ }^{38}$ however, VEGF-D may cooperate with VEGF-C in a COX-2-dependent manner. We previously reported that EP3 signaling activates AP-1 in fibroblasts. ${ }^{12}$ It has also been established that EP4 and a splicing variant of EP3 can activate adenylate cyclase, thereby elevating cAMP levels. These findings suggest that $\mathrm{PGE}_{2}$ may regulate lymphangiogenesis in these lymphedema models.

The treatment of lymphedema is currently based on physiotherapy, compression garments, liposuction, and occasionally surgery. ${ }^{39}$ However, efforts to reconstitute the lymphatic vessels and cure lymphedema are rarely successful. ${ }^{40}$ VEGF-C gene transfer via adenoviruses, adenoassociated viruses, or naked plasmids, as well as the application of recombinant VEGF-C protein, has been shown to stimulate the formation of new lymphatic capillaries and alleviate edema in preclinical animal models of lymphedema, ${ }^{41-43}$ suggesting the potential to restore lymphatic vessels in lymphedema patients. Furthermore, as seen in Figure $2 \mathrm{~d}$, the temporal changes in the interstitial pressure was significantly higher in the group treated with celecoxib. The difference of the pressure at 2 weeks between the two groups was not statistically significant; however, the pattern of the interstitial pressure was similar between the two groups, and the time to the peak of the pressure was delayed in celecoxib-treated mice. Thus, the difference of the pressure at 2 weeks between those treated with a COX-2 inhibitor and those without a COX-2 inhibitor was not statistically significant.

In conclusion, lymphangiogenesis, together with recurrence of lymph flow after surgical induction in the acquired lymphedema model, may be upregulated by endogenous PGs derived from COX-2. The development of a PG analog that mimics the biological activities of PGs will be a good option for the treatment of lymphedema in patients after surgical intervention.

\section{ACKNOWLEDGEMENTS}

We thank Yumiko Sone, Michiko Ogino, Kyoko Yoshikawa, and Osamu Katsumata for their technical assistance. We are grateful to Dr Patrick Hughes for linguistic assistance in the preparation of this manuscript. This work was supported by research grants (nos. 12470529, 12470539, and 12670094) from the High-Tech Research Center grant from the Ministry of Education, Culture, Sports, Science and Technology, Japan. This study was also supported by an Integrative Research Program of the Graduate School of Medical Science, Kitasato University.

\section{DISCLOSURE/CONFLICT OF INTEREST}

The authors declare no conflict of interest.

1. Alitalo K, Tammela T, Petrova TV. Lymphangiogenesis in development and human disease. Nature 2005;438:946-953.

2. Tammela T, Alitalo K. Lymphangiogenesis: molecular mechanisms and future promise. Cell 2010;140:460-476.

3. Erickson VS, Pearson ML, Ganz PA, et al. Arm edema in breast cancer patients. J Natl Cancer Inst 2001;93:96-111.

4. Petrek JA, Senie RT, Peters M, et al. Lymphedema in a cohort of breast carcinoma survivors 20 years after diagnosis. Cancer 2001;92:1368-1377.

5. Carter BJ. Women's experiences of lymphedema. Oncol Nurs Forum 1997;24:875-882.

6. Logmans $\mathrm{A}$, Kruyt $\mathrm{RH}$, de Bruin $\mathrm{HG}$, et al. Lymphedema and lymphocysts following lymphadenectomy may be prevented by omentoplasty: a pilot study. Gynecol Oncol 1999;75:323-327.

7. Oliver G, Alitalo K. The lymphatic vasculature: recent progress and paradigms. Annu Rev Cell Dev Biol 2005;21:457-483.

8. Wigle JT, Oliver G. Prox1 function is required for the development of the murine lymphatic system. Cell 1999;98:769-778.

9. Karkkainen MJ, Saaristo A, Jussila L, et al. A model for gene therapy of human hereditary lymphedema. Proc Natl Acad Sci USA 2001;98:12677-12682.

10. Majima $M$, Isono $M$, Ikeda $Y$, et al. Significant roles of inducible cyclooxygenase (COX)-2 in angiogenesis in rat sponge implants. Jpn J Pharmacol 1997;75:105-114.

11. Majima M, Hayashi I, Muramatsu M, et al. Cyclo-oxygenase-2 enhances basic fibroblast growth factor-induced angiogenesis through induction of vascular endothelial growth factor in rat sponge implants. Br J Pharmacol 2000;130:641-649. 
12. Amano $\mathrm{H}$, Hayashi $\mathrm{I}$, Endo $\mathrm{H}$, et al. Host prostaglandin $\mathrm{E}(2)$-EP3 signaling regulates tumor-associated angiogenesis and tumor growth. J Exp Med 2003;197:221-232.

13. Majima M, Amano $\mathrm{H}$, Hayashi I. Prostanoid receptor signaling relevant to tumor growth and angiogenesis. Trends Pharmacol Sci 2003;24:524-529.

14. Kubo H, Hosono K, Suzuki T, et al. Host prostaglandin EP3 receptor signaling relevant to tumor-associated lymphangiogenesis. Biomed Pharmacother 2010;64:101-106.

15. Katoh $\mathrm{H}$, Hosono $\mathrm{K}$, Ito $\mathrm{Y}$, et al. COX-2 and prostaglandin EP3/EP4 signaling regulate the tumor stromal proangiogenic microenvironment via CXCL12-CXCR4 chemokine systems. Am J Pathol 2010;176:1469-1483.

16. Hagendoorn J, Padera TP, Kashiwagi S, et al. Endothelial nitric oxide synthase regulates microlymphatic flow via collecting lymphatics. Circ Res 2004;95:204-209.

17. Kawamoto T. Use of a new adhesive film for the preparation of multipurpose flesh-frozen sections from hard tissues, whole-animals, insects and plants. Arch Histol Cytol 2003;66:123-143.

18. Schneider $M, N y$, de Almodovar $C R$, et al. A new mouse model to study acquired lymphedema. PLoS Med 2006;3:e264.

19. Cheung L, Han J, Beilhack A, et al. An experimental model for the study of lymphedema and its response to therapeutic lymphangiogenesis. BioDrugs 2006;20:363-370.

20. Jin da P, An A, Liu J, et al. Therapeutic responses to exogenous VEGF-C administration in experimental lymphedema: immunohistochemica and molecular characterization. Lymphat Res Biol 2009;7:47-57.

21. Földi E, Sauerwald A, Hennig B. Effect of complex decongestive physiotherapy on gene expression for the inflammatory response in peripheral lymphedema. Lymphology 2000;33:19-23.

22. Angeli V, Randolph GJ. Inflammation, lymphatic function, and dendritic cell migration. Lymphat Res Biol 2006;4:217-228.

23. Haarbrink $M$, Terhell AJ, Abadi GK, et al. Inflammatory cytokines following diethylcarbamazine (DEC) treatment of different clinical groups in lymphatic filariasis. Trans R Soc Trop Med Hyg 1999;93: 665-672.

24. Faour WH, Gomi $K$, Kennedy CR. PGE 2 induces COX-2 expression in podocytes via the EP4 receptor through a PKA-independent mechanism. Cell Signal 2008;20:2156-2164.

25. Rösch S, Ramer $\mathrm{R}$, Brune $\mathrm{K}$, et al. Prostaglandin $\mathrm{E}_{2}$ induces cyclooxygenase-2 expression in human non-pigmented ciliary epithelial cells through activation of p38 and p42/44 mitogenactivated protein kinases. Biochem Biophys Res Commun 2005;338: 1171-1178.

26. Hinz B, Brune K, Pahl A. Prostaglandin $E_{2}$ upregulates cyclooxygenase2 expression in lipopolysaccharide-stimulated RAW 264.7 macrophages. Biochem Biophys Res Commun 2000;272:744-748.

27. Cursiefen $C$, Chen L, Borges LP, et al. VEGF-A stimulates lymphangiogenesis and hemangiogenesis in inflammatory neovascularization via macrophage recruitment. J Clin Invest 2004; 113:1040-1050.
28. Su JL, Shih JY, Yen ML, et al. Cyclooxygenase-2 induces EP1- and HER2/Neudependent vascular endothelial growth factor-C up-regulation: a novel mechanism of lymphangiogenesis in lung adenocarcinoma. Cancer Res 2004;64:554-564.

29. von Rahden $\mathrm{BH}$, Stein $\mathrm{HJ}$, Puhringer $\mathrm{F}$, et al. Coexpression of cyclooxygenases (COX-1, COX-2) and vascular endothelial growth factors (VEGF-A, VEGF-C) in esophageal adenocarcinoma. Cancer Res 2005;65:5038-5044.

30. Timoshenko AV, Chakraborty C, Wagner GF, et al. COX-2-mediated stimulation of the lymphangiogenic factor VEGF-C in human breast cancer. Br J Cancer 2006;94:1154-1163.

31. Nakamura K, Radhakrishnan K, Wong YM, et al. Anti-inflammatory pharmacotherapy with ketoprofen ameliorates experimental lymphatic vascular insufficiency in mice. PLoS One 2009;4:e8380.

32. Ueno T, Suzuki T, Oikawa A, et al. Recruited bone marrow cells expressing the EP3 prostaglandin $E$ receptor subtype enhance angiogenesis during chronic inflammation. Biomed Pharmacother 2010;64:93-100.

33. Kamoshita $E$, Ikeda $Y$, Fujita $M$, et al. Recruitment of a prostaglandin $E$ receptor subtype, EP3-expressing bone marrow cells is crucial in wound-induced angiogenesis. Am J Pathol 2006;169:1458-1472.

34. Amano $\mathrm{H}$, Ando $\mathrm{K}$, Minamida $\mathrm{S}$, et al. Adenylate cyclase/protein kinase A signaling pathway enhances angiogenesis through induction of vascular endothelial growth factor in vivo. Jpn J Pharmacol 2001;87:181-188.

35. Orlandini M, Oliviero S. In fibroblasts Vegf-D expression is induced by cellcell contact mediated by cadherin-11. J Biol Chem 2001;276:6576-6581.

36. Mitchell PJ, Wang $C$, Tjian R. Positive and negative regulation of transcription in vitro: enhancer-binding protein AP-2 is inhibited by SV40 T antigen. Cell 1987;50:847-861.

37. Imagawa $M$, Chiu R, Karin M. Transcription factor AP-2 mediates induction by two different signal-transduction pathways: protein kinase $C$ and CAMP. Cell 1987;51:251-260.

38. Orlandini M, Marconcini L, Ferruzzi R, et al. Identification of a c-fosinduced gene that is related to the platelet-derived growth factor/ vascular endothelial growth factor family. Proc Natl Acad Sci USA 1996:93:11675-11680.

39. Radhakrishnan K, Rockson SG. The clinical spectrum of lymphatic disease. Ann NY Acad Sci 2008;1131:155-184

40. Baumeister RG, Seifert J, Wiebecke B, et al. Experimental basis and first application of clinical lymph vessel transplantation of secondary lymphedema. World J Surg 1981;5:401-407.

41. Saaristo A, Tammela T, Timonen J, et al. Vascular endothelial growth factor- $C$ gene therapy restores lymphatic flow across incision wounds. FASEB J 2004;18:1707-1709.

42. Karkkainen MJ, Saaristo A, Jussila $L$, et al. A model for gene therapy of human hereditary lymphedema. Proc Natl Acad Sci USA 2001;98:12677-12682.

43. Saaristo A, Veikkola T, Tammela $T$, et al. Lymphangiogenic gene therapy with minimal blood vascular side effects. J Exp Med 2002;196:719-730. 